Portland State University

PDXScholar

1977

\title{
An Evaluative Study of Client Satisfaction at a Mental Health Clinic
}

Dianne E. Carlton

Portland State University

Follow this and additional works at: https://pdxscholar.library.pdx.edu/open_access_etds

Part of the Social Work Commons

Let us know how access to this document benefits you.

\section{Recommended Citation}

Carlton, Dianne E., "An Evaluative Study of Client Satisfaction at a Mental Health Clinic" (1977).

Dissertations and Theses. Paper 1887.

https://doi.org/10.15760/etd.1886

This Thesis is brought to you for free and open access. It has been accepted for inclusion in Dissertations and Theses by an authorized administrator of PDXScholar. Please contact us if we can make this document more accessible: pdxscholar@pdx.edu. 


\title{
AN WVAIUATIVE SITDY OE OLIFNT SATISFACTION \\ A': A MENTAL, FENLTH CLINIC,
}

by

D.LANNE: E. CARLTON

A practicum submitted in partial fulfillment of the requirements for the degree of

\author{
MASTER OF SOCIAI WORK
}

Portland State University

1977 
TO THE OFFICE OF (FRADUATE STUDIES AND RESEARCH:

The advisor approves the practicum of Dianne E. Cariton presented June 1, 1977.

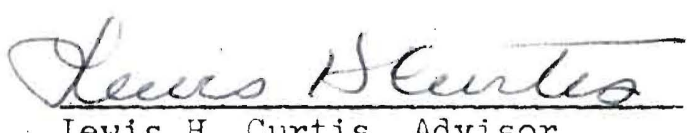
Iewis H. Curtis, Advisor 
PACE

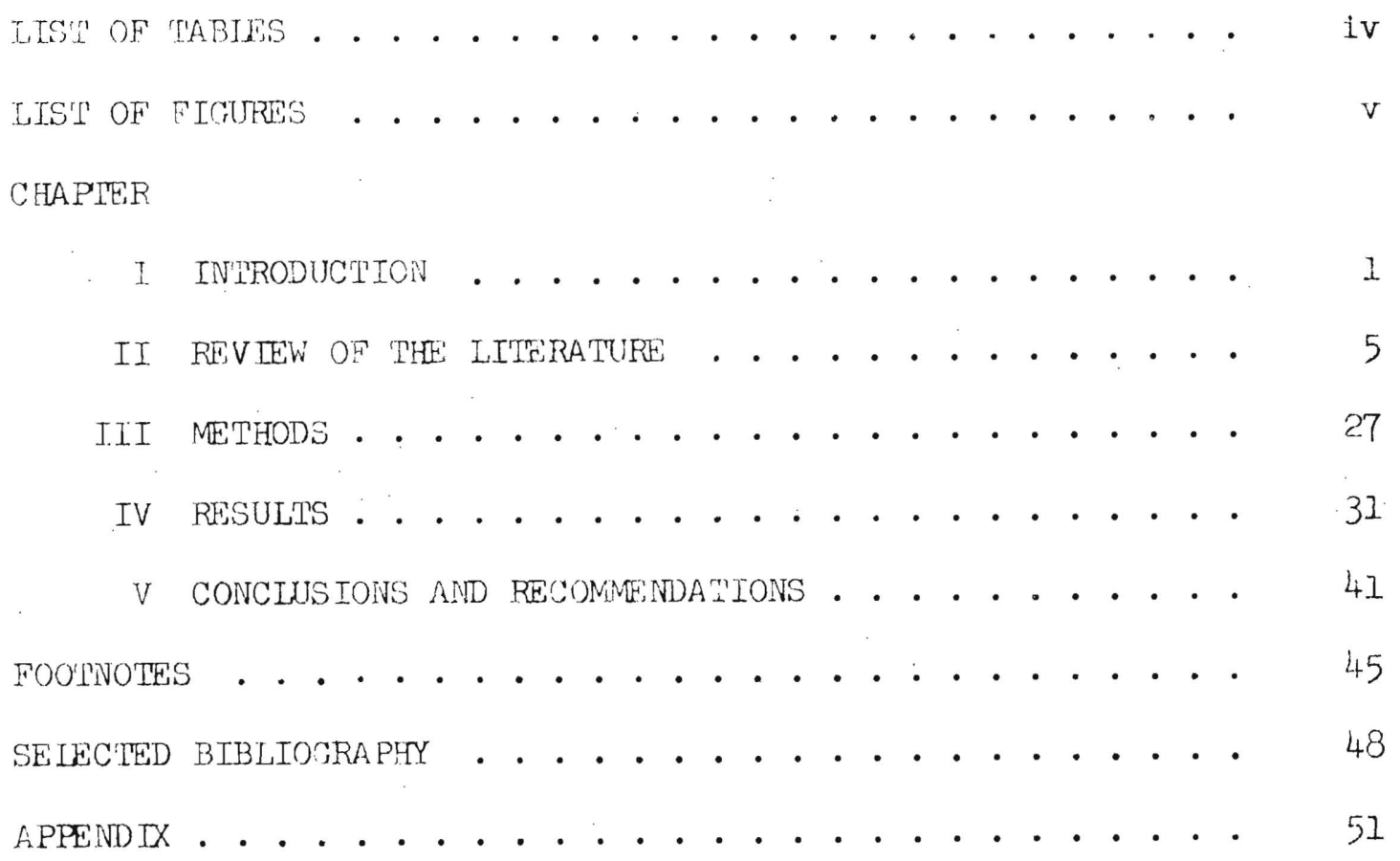




\section{LIST OF IABIES}

\section{PAGE}

TABIE

I Significance Test for Difference in Age . . . . . . 33

II Significance Test for Difference in Sex . . . . . . 33

III Demographic Information, Client Responses to Selected Questions, and Therapists' Evaluations of Goal Achievement............ . . 36

IV Client Evaluation of Toal Achievement/Therapist Evaluation of roal Achievement ......... 37

$\mathrm{V}$ Client Evaluation of Goal Achievement/Therapist Evaluation of Goal Achievement Listed by Number of Visits . . . . . . . . . . . . 


\section{LIST OF FIGURES}

\section{PACE}

FIGURE:

I 'Lvpes of evajuation . . . . . . . . . . 14

2 Relation of four data levels to theoretical approaches . . . . . . . . . 18

3 Evaluation process ............. 22 


\section{CHAPIER I}

\section{INTRODUCTION}

Evaluative research in the field of mental health is carried out pursuant to several goals. One is to study a very particular intervention on a very particular client (or client population) in a controlled way with the aim to test a theory of intervention. This form of research requires basically an experimental research design. It also requires rigorously defined and measured intervention and a good control for factors other than intervention. The requirements for this form of research are stringent and the number of such projects reported is, therefore, rare.

Another form of evaluative research is that done for the purpose of measuring effects of a program on the clients in the program. Some of these designs also require control groups and all require measurement of success against pre-stated goals. This has been the typical kind of research used to measure effects of large-scale, federal programs such as Head Start.

Another form of evaluative research, and that which is the subject of this project, is an accountability study. The purpose of the research is to give the administrator of a mental health clinic feedback about the success or failure of clients in his agency to reach therapeutic goals. The information can then be grouped by program or by therapist to yield data describing the effectiveness of each 
therapist. The design of this kind of research has no place for a control group. Each client is evaluated by his perceived achievement of his therapeutic goals, which he participates in setting, and his therapist's evaluation of his attainment of the the rapeutic goals.

As with each kind of evaluation, the accountability study presents questions of design and questions concerning the use of the data. Some researchers would say that accountability studies are useless because they say nothing about how goals are accomplished. It is definitely true that they make no contribution to theory, but that is not the stated goal of an accountability study. This presents the whole area of values. Those who make that criticism believe that what is needed in the mental health field is a firm theoretical base; those who use accountability studies believe that they, as administrators, should have good information upon which to base administrative decisions. It appears that each kind of evaluation has a valid goal and that the goals may be seen as of a different order.

\section{Factors in Particular Setting}

The present study was done as a pilot study for the Elahan Center for Mental Health and Family Living (formerly Clark County Mental Health) in Vancouver, Washington. This agency has recently undergone much change. About eighteen months ago there was a change of Directors. At about the same time, though unrelated, the agency was involved in a public scandal around the drug program. As a result of much inter-agency strife and the change in administration, few employes from the old staff remain. The new administration is 
dedicatedly behavioristic in therapeutic orientation, as are some of the therapists. Use of para-professionals in professional capacities is high and most of the para-professionals follow the behavioristic bent of' the administration.

The breakdown of therapist staff by education and degree is ten para-professionals and thirteen professionals. Duties of paraprofessionals vary from profram directors, who, in addition to administrative tasks, are primarily therapists, to the intake worker. Of the thirteen professionals on the staff, three are Ph.D. level psychologists, one is a Masters level psychologist, three are Masters level counselors, three hold Masters degrees in social work, one is a Masters level psychiatric nurse, one is an M.D. level psychiatrist, and one person has a certificate in alcohol studies. There are two second-year and one first-year graduate student from the Portland State University School of Social Work and a varying, large number of counselinfs students from Lewis and Clark College.

Elahan offers a wide variety of programs including general outclient, day treatment programs for three populations, disturbed children, elderly and psychiatric post-hospitalization clients. The agency accepts referrals from the courts, particularly juvenile status offenders, and substance abusers, both adult and adolescent. A large number of referrals also comes from the Washington State Department of Social and Health Services, the local administrative agency for public assistance funds. Certain employes at Elahan are responsible for the enforcement of the state involuntary commitment laws. Consequently, there is a diverse client population at Elahan though each therapist 
tends to work primarily with one major classification of client. Group, individual, fomily, and marital therapy are offered by the agency. The administration encourages group work. There are approximately 950 cases open at any given time at Elahan and about 1,715 client contacts are made each month.

The research activities at Elahan are new. There is much concern by the administration to prove that the agency is helping people and that the therapists are working effectively. This has created a good bit of anxiety on the part of some therapists, a factor which will be discussed in a later section. 
CHAPIER II

REVIEW OF THE LITERATURE

\section{Definitions}

Evaluative research in the field of mental health has to do with whether or not and how the therapeutic goals for a client or a group of clients have been met. This is a difficult process because therapeutic goals are difficult to define so that criteria can be found which are measurable and meaningful. There is disagreement between different therapeutic theorists as to what a legitimate goal for therapy is and even more disagreement on criteria used for measuring change. Another difficulty is that events other than therapy affect outcomes and those events are not available for investigation and control.

Regardless of difficulties and differences, researchers try to define evaluation. Weiss defines evaluation as "the study of program effects in terms of intended and unintended consequences for the target groups and institutions."I Korolope says:

Evaluation is defined as the act of making a decision concerning the effectiveness of some program or product on individuals or groups of individuals.

Clarkson's definition of evaluation is:

the technology whereby the output of a process or treatment is related to expressed goals in such a way that attainment or non-attainment of those goals can be measured in an objective way consistent with statistical techniques and a decision can be made concerning the effectiveness of the process or treatment under study. 3 
These three definttions say approximately the same things though Clarkson's seems to capture better the idea that it is the process, the treatment, that is the subject of the evaluation.

\section{History of Evaluative Efforts}

At the 1931 National Conference of Social Work, Cabot called

for internal evaluation and formulation of theory.

Let us criticize and reform ourselves before a less gentle and appropriate body takes us by the shoulders and pushes us into the street. 4

His concern went largely unheaded and no systematic research was begun. Until Eysenck published a review article in $1952,{ }^{5}$ the few published articles attempting to evaluate psychotherapy were therapists ratings of groups of clients as unimproved, improved, or much 1mproved. In 1952 Eysenck published no new results and none of his own, but in a f'ive page article reviewing other published research, he upset the psychoanalytic community by concluding that psychotherapy with neurotic clients was equally effective as no treatment at all. During the past twenty five years, many articles, and even books, have been published in answer to Eysenck. ${ }^{6}$ It seems as if the task was not really so difficult. Upon re-reviewing the articles Eysenck reviewed, Eysenck's methods of categorization and the source of his data for "spontaneous recovery" are questionable. In 1971, nineteen years later, Bergin reviewed the same articles Eysenck reviewed and arrived at different results by categorizing the studies differently. ${ }^{7}$ Malan has written an excellent article reviewing this whole argument historically. 8

In 1956 Leary published his Multilevel Measurement of InterPersonal Behavior. 9 This is a complicated, comprehensive assessment 
scale he designed as a research tool. The assessment is to be completed before and after therapy and change noted. Using the scale, Leary reports statistically significant positive change.

This difference justifies the summary statement that the experlence of being in individual psychotherapy for a period of approximately six months leads to significantly greater change in personality (at the symptomatic level) than does the experience of being on a waiting list put recelving no psychotherapy during an equivalent period. 10

It is interesting that Ieary's system of measurement and results are not mentioned in the articles arguing the effectiveness of therapy.

In 1956 the Menninger Clinic announced the beginning of a research project designed to measure the effects of psychotherapy. ${ }^{11}$ The final report was not published until 1972. ${ }^{12}$ Malan says of the Menninger Foundation report:

Yet the most influential and ambitious of all forms of psychotherapy, that based on psychoanalysis, has yielded almost nothing - a matter for shame and dispair - until it has been saved at the last moment by the Menninger Foundation's final report. 13

During the 1960s Truax reported positive effects in clientcentered therapy related to therapist qualities of high empathy, non-possessive warmth and genuineness. 14

In the late 1950s behavior therapy began to report positive results, though Malan reports that early studies were done using volunteers rather than clients. 15 The behaviorists are in an envyable position for research because their goals are modifications of observable behaviors and measuring observable behavior is much less complicated than measuring intra-psychic conflict.

In 1958, 1961 and 1966 the American Psychological Association held conferences on Research in Psychotherapy. 16,17,18 The first 
conference was concerned with the need for outcome research. At the second conference, papers were delivered reporting outcomes in psychotherapy. At the third conference, however, research in behavior therapy and uses of ISD in research dominated. Psychotherapy papers were limited to studies of the process rather than the outcome of psychotherapy except for a report of semi-final results of the Menninger Foundation study. The American Psychological Association has not held a conference on research since 1966.

Malan reports that motivation to do and interest in outcome research in psychotherapy in the mid-1960s was low because of the difficulty of isolating variables and because it was felt that research had little impact on practice. 19

State of the Art Today

Today there is a need for evaluative research because funding agencies demand proof that moneys are being spent effectively. Directors of mental health clinics want information to guide their managerial tasks.

Increasingly, legislation and administrative regulations require evaluation of social programs, large sums of public monies are being expended and results are publicized and considered in decision-making councils.

Contributing to the increasing fervor about evaluation are unprecedented pressures from both internal sources, such as managers demanding more extensive, accurate and easily accessible information for decision making purposes, and from external agencies, particularly legislative and funding source requirements. 21

Burck introduces the term "accountability," a popular term today in education and mental health research.

Money appropriated for the training of mental health professionals for settings of therapeutic practice may not 
flow freely forever without some factual evidence of positive results. 'Accountability' is in vogue. There is an urgent need for outcome research. 22

Breedlove and Markson stress the importance of evaluative regearch to theory building. Breedlove, speaking more directly to social work, insists that research is valueless unless it makes such a contribution.

The study demonstrating positive results without showing how they were achieved is as useless as the study with negative results which does not explain why the treatment, was ineffective. . . The evaluative study, then, must test theory about a social problem and its treatment, not substitute empirical investigation for theoretical understanding. 23

Evaluation is required if knowledge of the efficacy of a modality or a program is to be other than impressionistic. 24

In spite of the demand, behavior therapy is the only area that has offered relatively simple measures. Psychotherapy research is more ambitious and more complicated; workers still cannot agree on validity and reliability of measures. As a result, techniques developed to suit behavior and learning theory, that is, measuring observable behaviors, are being applied to other styles of therapy.

The Process of Evaluation

The beginning of evaluation in a mental health agency can be an anxiety-producing situation which becomes detrimental to the smooth operation of the agency. Being evaluated implies to the therapist that someone is distrustful of his abilities and is going to be snooping on him and intruding on his time by requiring procedures to prove something which the therapist thinks he already knows. The manner in which the agency management and the evaluator go about doing a research project is important to avoid upset and to insure good data from cooperative therapists. 
Weiss describes a general atmosphere of antagonism, which is hard on the evaluator's ego, between the therapeutic staff and the evaluator.

Program staff have rarely liked evaluators poking their noses into the operation of programs or measuring outcomes. Whatever soothing explanations are offered about 'testing program concepts' or 'accountability to tax payers,' the evaluator is still a snoop. 25

Therapists are not always unrealistic or paranoid about evaluation because a possible conclusion is always to modify the therapy or discontinue a program.

Evaluation has always had explicitely political overtones. It is designed to yield conclusions about the worth of programs and, in so doing, is intended to affect the allocation of resources. The rationale of evaluation research is that it provides evidence on which to base decisions about maintaining, institutionalizing, and expanding successful programs and modifying or abandoning unsuccessful ones. 26

Koroloff suggests that strengths and weaknesses for research activities be defined during the planning stage of research. She has devised a scale, "Organizational Influences in Evaluation" as an aid in determining areas where training and information are needed to help deal with staff resistance. 27

One very important point of evaluative research is that

All staff who are primarily affected by the evaluation should have input into the formation of the evaluation. Their input need not be of a technical nature but they should at least have the opportunity to react to what is being used as a basis for the evaluation. 28

Moursund points out that an evaluator, like everyone else, cannot be completely objective but that he should be very aware of his own internal value structure so he can deal with the values of others. 29 He also points out that it is necessary for the evaluator to understand the theory which is the subject of the evaluation. He concludes 
that he believes it is better for the evaluator to be a specialist in the subject area of his evaluation rather than a professional researcher. 30

When evaluation is performed internally, that is, when the evaluator is a staff member and not a contractor with the agency, he is commonly part of the administrative part of the staff rather than part of the therapeutic staff. Therapists, therefore, identify him with the administration, an alliance which adds to the suspiciousness already discussed. 31

Goals of Evaluation

Goals of therapy and goals of research are different and this discussion will be limited to goals of research.

Weiss states that if researchers had to answer the question, "What are evaluation's goals?" the appropriate answer would be:

"Evaluation should make for better human services and wiser allocation of resources among and within programs."32

Some researchers maintain, that among other things, discerning the therapeutic goals of a program is a valid goal for the evaluation. 33

The understanding of the processes by which clients improve is described by some authors as the only legitimate goal of evaluative research. Others maintain that the outcome is more important. Dividing research efforts into process studies and outcome studies is one classification system.

Zusman believes outcome evaluation is the most important because it is directly related to the purpose of treatment, which is to make the patient better. 34 Breedlove, on the other hand, believes that 
unless research makes a contribution to theory, that is, unless it describes the effects of particular treatments on particular client populations, it is useless.

Findings are no substitute for a theory, so if the evaluative research design does not reflect a unified theoretical orientation, the findings, no matter how clear-cut, no matter whether positive or negative, have no lasting value. 35

Breedlove's reason for valuing contributions to theory so highly is that there is a great, unmet need for knowing which treatments are effective with what client populations and that that need is of a higher order than simply proving that a program is successful for the purposes of so advertising without particularly describing what happens in the program that leads to successful outcome.

Evaluative studies can succeed in establishing the effectiveness, or lack of it in a particular situation only to the extent that the method of intervention is both conceptually and operationally defined in a way clearly related to the social problem being treated. 36

Based on this value, Breedlove describes three levels of contribution from evaluative research.

Depending on how thoroughly it was conducted, the evaluative study may contribute at one of three levels to social work practice: data about a particular service or treatment and its results, that is, the practice effects; data about the success of a particular social agency program, that is, program effectiveness; and new understanding about a partiç; ular practice theory, that is, professional effectiveness. 37

Many other workers agree that knowledge and understanding of the process is more important than knowledge of the outcome. Among them is Weiss who acknowledges that "The why is often just as important to know as how well the program works. ${ }^{38}$ Moursund believes establishing causation is the essence of evaluation. 
Good evaluative research must usually concern itself with causation, that is, what set of circumstances causes what effects. But, while causal inference comes very naturally to us in our everyday thinking, it is difficult to manage in a controlled research situation. There are three major indicators of causation that researchers tend to look for: (1) the relatedness (that the 'cause' and 'effect' do occur together in the data), (2) time order (that the 'cause' precedes the 'effect'), and (3) the elimination of other possible causal factors. Evaluation involves an effort to establish a set of necessary and sufficient conditions for the occurence of some effect of interest. 39

Mullen and Dumpson criticize specific research projects for failing

to adequately describe process.

Many projects fail to reach their goals because the following question has be inadequately considered: On what basis and toward what end will who do what to whom, for how long, with what effect, at what cost, and with what benefits? This criticism applies not only to the negative-outcome projects, but to many of those with positive outcomes as well, for even if the effects are judged to be positive, we are usually not sure why. Most of the positive-outcome studies did not adequately define and measure the nature of the interventions; thus, how are we to repeat or learn from successful programs? 40

Chommie addresses the process/outcome problem consldering needs

of administrators for outcome results.

Emphasizing program outcomes may represent the preferred approach for evaluation that meets the informational needs of policy-makers. But as a long-range strategy, this approach may not be entirely satisfactory either to program administrators, program staff or clients, who expect relatively quick feedback of relevant information so that the delivery of services may be modified as necessary. The information needs of those most directly involved in the program may best be met be a strategy that centers the research on the processes of program development and implimentation.

Clearly, both process and outcome are proper concerms for evaluation. The authors contend, however, that giving increased attention to process, rather than focusing strictly on outcome, may have significant information payoff to the various people involved in social programs, and, in turn, may lead to a clearer understanding of how and why change does or does not occur. . . Social planners and policymakers remain abysmally ignorant of how change is actually produced. 41 
Weiss describes three evaluative models which

A.l. deal in outcome data. All present evidence of the effectiveness of programs in attaining their goals, but each is apt for answering a different order of question and supplying information for a different type of decision. 42

Her three models are social experimentation, traditional evaluative research and accountability systems. These three models are designed to provide information for three different kinds of decisions, policy decisions, strategic (managerial) decisions, and tactical decisions. 43 Which model is chosen depends on the goals of the research, which depends on the needs and values of the instigator of the research.

Scriven makes a distinction between formative and summative evaluation, formative dealing with a project during its life with data providing feedback for immediate adjustments to the program and summative dealing with the program before it starts and after it is finished to determine whether or not its goals were met. 44

Koroloff has adopted Scriven's distinction and added case management.

\begin{tabular}{lll} 
Types of Evaluation & Type of Decision & Type of Action \\
\hline Case Management & $\begin{array}{l}\text { Determine effectiveness } \\
\text { of a program on indi- } \\
\text { vidual }\end{array}$ & $\begin{array}{l}\text { Continuance of } \\
\text { treatment }\end{array}$ \\
Formative & $\begin{array}{l}\text { Determine effectiveness } \\
\text { of parts of program on a cation } \\
\text { group of individuals }\end{array}$ & $\begin{array}{l}\text { Program Modifi- } \\
\text { Sumative }\end{array}$ \\
$\begin{array}{lll}\text { Determine overall } & \text { Deletion or addition } \\
\text { effectiveness of a } & \text { of programs, allocation } \\
\text { program } & \text { of money }\end{array}$
\end{tabular}

Figure 1. Types of evaluation 45 
Moursund comments that the formative/summative dichotomy is

artificial and that strict comitment to formative or sumative re-

search could lead to loss of information and impediment of services.

Unfortunately for the neatness of such a distinction, most programs don't seem to function this way. Evaluation is used at many points along the way, and may often serve simultaneously in a formative and a summative way. Indeed, it seems desirable that this should be so: if one is to go to the considerable trouble and expense involved in carrying out research, as much information as possible should be gained - and used - from data gathered. It would seem unnecessarily wasteful to study what some program should aim at without looking also at how close it is coming to those desired goals. Similarly, summative research should not only indicate whether goals are or are not being met but also give some hints as to why or why not and suggest the relative appropriateness of various goals in the context of the program's success or failure in reaching them. 46

Certainly, the same comments apply to the process/outcome distinctions.

Goals of Therapy

The goals of therapy vary according to theoretical framework. Whitehorn, a psychiatrist, discusses the goals of psychotherapy. "First I can offer the formula: 'The goal of psychotherapy is health'" 47

If one postulates more or less specific intrapsychic conflicts as the pathogenic processes causative or more or less specific morbid reaction types or mental diseases, then the goal of psychotherapy can be fairly definitely specified as being: to reverse the phthogenic process by resolving the intrapsychic conflict. 48

Measuring intrapsychic conflict is a difficult task. As Volsky points out, measuring the global variables of defensiveness, anxiety levels and problem solving abilities are difficult and further, the same result may have different meaning for different clients depending on the total pathogenic picture and change may be desirable in one direction for one kind of client and in the other for another. 49 
As discussed in a previous section, the behaviorists are in an envyable position because their goals are easily measurable. Workers of other theoretical frameworks, however, feel that behavioral goals do not properly reflect the complexity of the human personality or situation.

This leads to the final point towards which everything has been converging. Strupp and Bergin repeatedly emphasize the lack of impact of research on clinical practice; one American researcher after another expresses his disillusion with research in general. Surely much of this state of affairs is due to a single factor, namely the failure to design outcome criteria that do justice to the complexity of the human personality. Once this is fulfilled, statistically based research results with direct clinical applications follow immediately. 50

Leary's diagnositc and research instrument was designed with this problem in mind. It is a complex system and yet he warns: "No eightdigit code can summarize the richness of an individual." 51 And:

The interpersonal system of personality diagnosis was developed as a research tool. The main criteria which guided the construction of this model were that it should be objective and that it should pay respect to the complexity of human nature. 52

The Rogerians use the Q-Sort and the MMPI. The Menninger Clinic designed research instruments to suit analytic needs. The difficulties are that no one of these systems enjoys wide-spread acceptability, reliability and validity are questioned, and use and the administering and interpreting of the tests requires special knowledge.

Millon helps to make sense out of understanding research outcomes and methods by discussion acknowledging the differences in theoretical frameworks. He points out that the question "What is psychopathology?" is answered differently by subscribers to different theories. 
These theories have not only grown out of different historical traditions and professional orientations, but, more importantly, have also typically looked at different types of data for their concepts and research. Four data levels may be usefully differentiated, they are: (1) biophysical data, such as neuro-physiological process and anatomical defects, most frequently gathered in physical examinations and laboratory tests; (2) intrapsychic data, such as unconscious conflicts and defensive processes, usually inferred from therapy verbalizations, dream recollections and projective tests; (3) phenomenological data, such as self-perceptions, feelings and attitudes, expressed in and inferred from conversations, formal interviews, and personality inventories; and (4) behavioral data, such as the frequency of various forms of overt activity, typically recorded in systematic fashions by observers. 53

The purpose of thinking in this way is to facilitate integration of knowledge even though knowledge is pursued in a segmented fashion. 54 Figure 2 is Millon's work and is presented to aid in that understanding.

In a later section dealing with the advantages and limitations of the four data sources, Millon reviews the difficulty in measuring intrapsychic conflict. However, he encourages researchers to pursue methodology appropriate to the intrapsychic schools.

Although it may be that more fruitful research alternatives are available, the 'reality' of intrapsychic events cannot be dismissed. The inevitable difficulties, and the marked paucity of reliable and valid instruments, should serve as a challenge, giving the scientist all the more reason to devote his energies to articulating the amorphous stream of intrapsychic events, and to developing methods by which this rich body of data can be transformed into researchable variables. 56

He also encourages the same standards for research be used when judging intrapsychic based research as for other kinds of research. "Certainly intrapsychic researchers cannot dismiss these criteria cavalierly and then expect sensible scientists to take their work seriously." 57 


\begin{tabular}{|c|c|c|c|c|}
\hline & Biophysical & Intrapsychic & Phenomenological & Behavioral \\
\hline Basic Model & Disease & Adaptation & Dissonance & Learning \\
\hline $\begin{array}{l}\text { Definition } \\
\text { of Pathology }\end{array}$ & $\begin{array}{l}\text { Biological dys- } \\
\text { functions and } \\
\text { dispositions }\end{array}$ & $\begin{array}{l}\text { Unresolved con- } \\
\text { flicts, repressed } \\
\text { anxieties }\end{array}$ & Self discomfort & $\begin{array}{l}\text { Maladaptive } \\
\text { behavior }\end{array}$ \\
\hline $\begin{array}{l}\text { Thpes of } \\
\text { Patioulogy }\end{array}$ & $\begin{array}{l}\text { Traditional } \\
\text { psychiatric } \\
\text { disorders }\end{array}$ & $\begin{array}{l}\text { Symptom disorders, } \\
\text { character patterns }\end{array}$ & $\begin{array}{l}\text { Impoverishment, } \\
\text { disorganization }\end{array}$ & $\begin{array}{l}\text { Numerable specific } \\
\text { behavioral symptoms }\end{array}$ \\
\hline $\begin{array}{l}\text { Causes of } \\
\text { Pathology }\end{array}$ & $\begin{array}{l}\text { Heredity, consti- } \\
\text { tution, defects }\end{array}$ & $\begin{array}{l}\text { Instinct depriva- } \\
\text { tion, childhood } \\
\text { anxieties }\end{array}$ & $\begin{array}{l}\text { Denied self- } \\
\text { actualization }\end{array}$ & $\begin{array}{l}\text { Deficient learning, } \\
\text { maladaptive } \\
\text { learning }\end{array}$ \\
\hline $\begin{array}{l}\text { Types of } \\
\text { Concepts }\end{array}$ & $\begin{array}{l}\text { Operational defi- } \\
\text { nitions, intervening } \\
\text { variables }\end{array}$ & $\begin{array}{l}\text { Hypothetical con- } \\
\text { structs, interven- } \\
\text { ing variables }\end{array}$ & $\begin{array}{l}\text { Hypothetical con- } \\
\text { structs, interven } \\
\text { ing variables }\end{array}$ & $\begin{array}{l}\text { Intervening varia- } \\
\text { bles, operational } \\
\text { definitions }\end{array}$ \\
\hline $\begin{array}{l}\text { Major } \\
\text { Concepts }\end{array}$ & $\begin{array}{l}\text { Genes, temperament, } \\
\text { constitution, } \\
\text { defects }\end{array}$ & $\begin{array}{l}\text { Instincts, ego, } \\
\text { unconscious, de- } \\
\text { fense mechanisms }\end{array}$ & $\begin{array}{l}\text { Self, self-regard, } \\
\text { Eigenwalt }\end{array}$ & $\begin{array}{l}\text { Conditioning, re- } \\
\text { inforcement, } \\
\text { generalization }\end{array}$ \\
\hline Data & $\begin{array}{l}\text { Heredity, anatomy, } \\
\text { physiology, bio- } \\
\text { chemistry }\end{array}$ & $\begin{array}{l}\text { Free association, } \\
\text { memories, dreams, } \\
\text { projective tests }\end{array}$ & $\begin{array}{l}\text { Interviews, self- } \\
\text { report of conscious } \\
\text { attitudes and } \\
\text { feelings }\end{array}$ & $\begin{array}{l}\text { Overt behavior } \\
\text { observed and re- } \\
\text { corded objectively }\end{array}$ \\
\hline
\end{tabular}


In his comments on behavior orlented research, he captures the essence of the argument that just because a behavior or event is observable and quantifiable does not necessarily mean that it is worth observing or quantifying.

The virtue of performance tasks is their objectivity, their quantifiability, and the ready availability to normative data. Questions arise, however, as to the relevance to psychopathology of these highly specific measures, that is, whether the refined and precise data they gather capture anything more than the most obvious and trivial aspects of the pathological process. That they enable the researcher to specify accurately what he is measuring is no guarantee that he is measuring anything worthwhile. 58

Millon points out that research should be designed to fit the problem, rather than performing a particular research because the methods are clear.

Thus, as with the practice of psychotherapy, the research novice should be broadly skilled and open-minded, capable of selecting methods that are suited to the solution of significant problems, rather than limiting himself to problems that fit the narrow-band of his research competencies. 59

Breedlove warns against doing research just because it looks

like research when a case study would give more information for developing a practice theory.

Practitioners and methods teachers are well advised to insist on intensive individual client studies and to forgo the mystique of large sample size. Such an approach is far liklier to provide the kind of information needed to improve practice than does traditional evaluative research. Social workers should beware of mistaking the trappings of scientific investigation - statistics and large sample sizes - for science itself. Science provides understandings, and neither sample size nor statistics can do that, although at times they may be useful in that regard. 60

Methods of Evaluation

Methods of evaluation are variable depending on the goals of the therapy and the goals of the research. 
Breedlove describes an experimental study designed to yield his

valued end of theory building.

The evaluative study is carried out through six interrelated tasks: (I) randomly assigning individuals drawn from an identified population to control and experimental groups; (2) providing an experimental treatment for the experimental group and not for the control group; (3) measuring the results for both groups by clear outcome maasures, which are (4) representative of value criteria, and which (5) are measured against relatively stable variables describing the context in which the experiment or evaluative study takes place; and (6) development of a theoretical framework within which all the preceding five tasks can be integrated. These six tasks represent a continuum of progressive utility of the results of evaluative studies. . . . The quality of a given study's contribution depends on the care with which these six issues have been handled. 1

Before describing other models, a discussion of goals is necessary. The kinds of evaluative research engaged in currently involve specifying and defining goals at all levels of operation: goals for the agency, goals for the therapists, goals for particular programs within the agency and goals for individual clients. Goals cannot be evaluated directly because they are general, value statements so objectives with behavioral pinpoints or criteria are defined for each goal. The criteria are to be quantifiable and thus measurable. There should be agreement within an agency that the goals are valuable and meaningful and that the objectives and criteria are adequate measures or indicators of achievement of the goals. 62 Moursund points out that criteria are difficult to set and that sometimes researchers describe criteria that fit the definition of criteria well but do not adequately measure the goal. 63

Koroloff mentions that decision rules should be designated during the planning stage to avoid manipulation of data. Usually programs meet 
some objectives and not others and the relative importance of each objective should be declded before the data 18 in. 64

Weiss offers a formulation for what she calls traditions.

evaluative research.

1. Finding out the goals of the program;

2. Translating the goals into measurable indicators of goal achievement;

3. Collecting data on the indicators for those who have been exposed to the program;

4. Collecting similar data on an equivalent group that has not been exposed to the program (control group);

5. Comparing the data on the program pofticipants and controls in terms of goal criteria.

Weiss includes the use of a control group for comparison to the treated group, which is not unlike an experimental design. The following models do not require a control group as results are measured against desired outcomes (goals). Comparison with a control group would yield more and interesting data, but it is not a requirement of the design.

Koroloff describes goal attainment scaling:

In Goal Attainment Scaling a set of goals is defined for each client, and a distinct rating scale developed for each goal. This allows the scale to be related directly to the client's problems which is a great advantage if the clients in an agency are very different. It is also possible to allow the client some direct input into the goals against which his treatment is evaluated. 66

Koroloff's model for program evaluation is presented on the following page. This process is consistent with her description of formative and summative evaluation, systems designed to provide information for decision-making. 


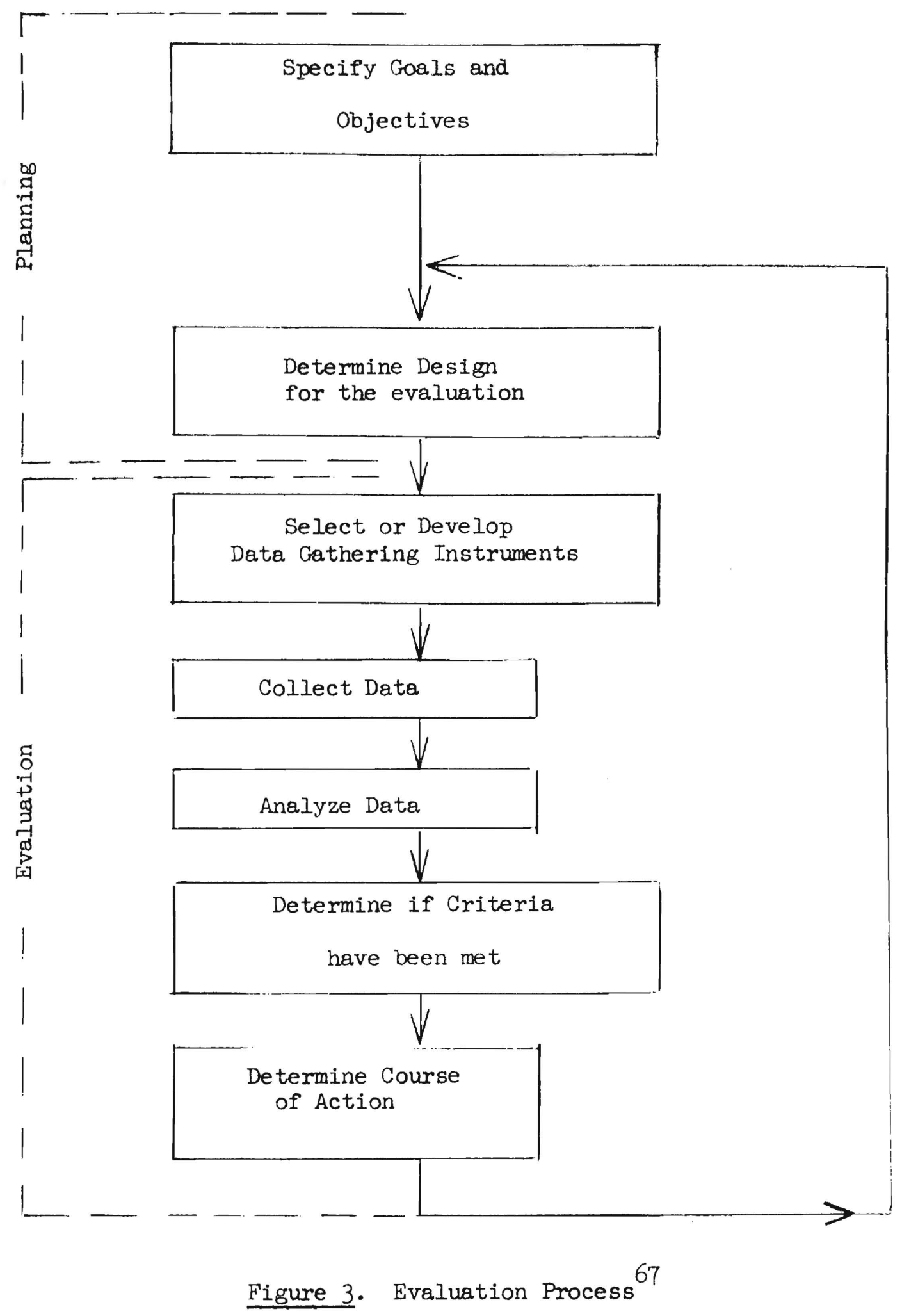


Moursund points out that program evaluation and program planning are circular, that nelther makes sense by 1tself. He sees the process as more circular than linear. 68

Segal lists several questions involved in outcome.

(1) What is desired?

(2) What are the raw materials?

(3) Given the limitation of the type of raw material, what techniques are available to achieve one's goal?

(4) Who applies these techniques?

(5) What is the technician's level of competence?

(6) In what type of envifonmental conditions are the se techniques applied?

He introduces some considerations, particularly concerning therapists abilities and clients' capabilities and life situations, which are not specified in the previous models.

Finally, Breedlove criticizes the narrowness of some evaluative efforts.

Some evaluative studies tend to separate technology from values, action from thinking, process from outcome, objective outcome criteria from subjective outcome criteria, when the purpose of the evaluative study is to synthesize all these things and to promote undersfanding of interventional processes be revealing their effects.

\section{Issues in Evaluation}

Koroloff very adequately describes seven issues in evaluation. 71

1. Confidentiality - Traditionally client-theraplst communication has been considered privileged. Much of this principle has been codified into the legal system and into professional ethics systems. The process of evaluation, except for a private practioner evaluating his own practice, violates that confidentiality.

2. Staff Involvement - The issue is whether or not to involve the staff. Information is heavily on the side of as much involvement 
and participation as possible as that facilitates acceptance and cooperation of the research. The evaluator is in an undesirable position if the staff provides him with skimpy or unreliable data.

3. Dissemination and Use of Results - Again, this is an ethical question including questions of confidentiality. When administrators use results for community politicking, they are breaching the confidentiality of some clients though they are not named.

4. Informed Consent - The issue is whether or not consent of clients is required. One argument is that consent would skew results. The other argument is that people have the right to know what records are being kept concerning them. Certainly, it appears as though a client would have good case for legal action if his case were used for study and consent had not been requested or had been requested and denied.

5. Control Groups - There are many 1ssues around control groups. One is the propriety of withholding treatment. Another is that there are not perfect controls in human studies. Another is a methodological question of whether or not they are necessary to achieve meaningful data.

6. Objectivity - Should the evaluation be done by someone on staff (internal) or by a consultant (external)? There are arguments that each is more objective than the other: internal evaluation is questioned because it is important for the agency to be successful; external evaluation is questioned because consultants who deliver negative results may not continue to find jobs.

7. Measurement of Therapeutic Relationships - One side of this 
argument is that only results are important and the other side is that only the therapeutic relationship is effective and that cannot be measured.

Weiss discusses, interestingly, the politics of evaluation. One point is that negative results should not necessarily lead to abandonment of a program but to its improvement. She describes a fear that negative results may lead to premature abandonment of programs and an abandonment of evaluation. ${ }^{72}$ Another point is that the many negative findings indicate (insofar as they are not an artifact of primitive research methods) serious shortcomings in the theoretical base of knowledge of what factors produce change, of program development, of management, and of the fragmentation due to lack of cohesiveness in our whole health care delivery system. ${ }^{73}$

It is time that we recognized the fallure of our moderate, piecemeal, cheap solutions to basic social problems. They have been tried, and evaluation research has found them wanting. Bold experiments are called for. It is a fraud to perpetuate variations on outmoded solutions to problems that are rooted in our system of social stratification. If more and more services to the poor do not enable people to move out of poverty, perhaps we have to look to ways of 74 redistributing income so that the poor are no longer poor. ${ }^{4}$

Her summary presumes research is correct and the system is lacking.

In the deepest sense, there is nothing null about recent evaluation research. The newly-visible large-scale evaluations are progressively disclosing the bankruptcy of piecemeal approaches to social programing. This is as important a conclusion as evaluation can provide. 75

Weiss leaves delivery of adequate service back at the drawing board, which is where Breedlove found it. He is correct; a theoretical framework is seriously lacking and program evaluation and accountability studies are not going to provide it. However, program evaluation and accountability studies are undertaken for other reasons, valid reasons, 
though perhaps not as important a reason as developing a theoretical base. 
CHAPIER III

METHODS

Elahan uses a modified Goal Oriented Record System for each client. Using this system, the client and therapist set goals for the client to achieve by the end of therapy. The question under study is whether or not the client achieved his goals. The original design called for the client to be interviewed by telephone by a trained interviewer (not the therapist) at termination. Also at termination, the therapist was to indicate in the client's file whether or not goals were achieved. The client was to be reinterviewed in three months and again in six months to see if changes made in therapy (achievement of goals) were still in effect. The date of termination is not always absolute; that is, clients sometimes finish an eight week group but then come back soon for another reason, or, more often, a client drops out of therapy and the case is not formally closed because the therapist thinks the client may come back. Thus, there is great disparity between the date the client was last seen and the date of termination. As a result, the design of the evaluation was modified to a) interview the client as soon as possible after termination, b) record the therapist's evaluation of goal achievement, and c) interview the client again in six months from the date of the first interview.

This resulted in a loss of data for this pilot project because six months have not elapsed since interviewing was begun. 
It is the intension of the agency to interview all clients, that is to do a census rather than a sample of the client population. Certain clients, however, are not included in the study. Following is a list of those and the reasons they are not included.

1) Clients who dropped out of therapy after intake or intake and one session will be excluded because the question of interest is whether or not goals were attained in therapy. It is felt that because there was no therapy, the question becomes meaningless.

2) Clients who are only in the involuntary commitment program will not be interviewed because they are not seen at the Elahan facility but by Elahan personnel at Columbia View Hospital and the same record-keeping system is not used.

3) It is unavoldable to exclude clients who are unreachable. This group includes a) deceased clients, b) clients who have moved from Vancouver, c) clients whose whereabouts is unknown (frequently because they are not known at the telephone number they gave the agency), and d) any client who was not reachable by telephone in three attempts. Thus, the study is limited to ambulatory clients who participated in therapy for at least more than two sessions and who are rather easily reachable. This provides some possible distortion of data.

\section{The Instrument}

The instrument is a questionnaire (a copy of which can be found in the appendix) to be administered by a trained interviewer over the telephone. The front page is not part of the questionnaire; it is information gathered from the client's file. Items nine and ten require some explanation. 
Item nine, the severity scale, is a rating of dysfunction in life roles, 0 being no dysfunction to 6 , grave dysfunction. This assessment is gathered at intake. While one person is scheduled to do most intakes, in fact several therapists do intakes. There is much doubt about the reliability of this rating because it is done after only one brief contact, frequently by a non-professional person, and by different people. Additionally, it is not completed on most intake forms, so not much data was generated from its inclusion here. Item ten is taken directly from the therapist's treatment plan and becomes the object of question four in the interview. The questionnaire itself is clear. More was asked than simply whether or not goals were met. In fact, the questionnaire is appropriate for clients who do not complete more than two sessions. Four interviews with such clients were completed and yielded interesting results, though they are not measures of goal achievement.

Because it is intended to interview all clients, no attempt was made to randomize the interviews completed for the pilot study. Originally, several people were scheduled to work on this project and all terminations during the period were to be considered and appropriate clients called. However, for various reasons, only one person worked on the project and only part of the available client files were reviewed. For purposes of the agency's pilot project, this appears to make no difference as clients in the study appear to be fairly representative, that is, they are from various programs, various therapists and various client populations. It is not known, however, 
if the group is representative on absolute comparisons of case-ciosing by therapist and by program. For the purposes of the pilot study, the number and kinds of respondents is adequate. 
CHAPIER IV

RESULTS

Fifty-one cases were chosen from the most recent lists available of terminations. Choice was made on the basis of rules discussed in the previous section. Out of the 51 attempts, 16 questionnaires were complete for clients who attended three or more sessions, 4 were complete for clients who attended two sessions or fewer, and 31 questionnaires were incomplete.

The breakdown of reasons for the incompletions is: 20 respondents had moved or for whatever reason were not known at the telephone numbers they had given the agency; 8 respondents were not reached after three telephone attempts; I respondent was reported by a relative to have been too $i l l$ to respond; I respondent objected to having had her case closed, though she had not been seen at the clinic for several months; and I respondent claimed never to have been a client at Elahan even though her name and telephone number matched those in the file. By agency records, this client is a 16 year old female who had been seen five times. An adult answered the telephone and was present as the interview was attempted so it is possible she could not respond for reasons of confidentiality. This respondent could also be classified as a refusal.

The largest category of incomplete questionnaires, 20 respondents who were not at telephone numbers given the agency, breaks down further. Eight of the 20 were telephone disconnects, family members not knowing 
whereabouts of respondents, or the person answering the telephone not ever having heard of the requested party. Five of the 20 were adolescents who at the time of treatment were in group or foster care and were no longer there. Some had returned home, to other parts of the state, one had gone to a different foster home and one had run away, reportedly to California. Of the remaining 4 of the 20 , two had moved out of state, one gave a telephone number which was not a known exchange, though the address indicated 1t should have been a local number, and one reported having moved to Portland but Portland had no listing for him.

For these 20 cases, attempts were made using telephone directories and information operators, where indicated, to find the client. Files were rechecked when that was indicated. There is some reason to believe that scme people gave the agency an incorrect telephone number though certainly no motivation can be ascribed to this, it could be an error or it could be purposive. Mostly, this seems simply to be a mobile population.

Of the two groups of respondents, the respondents who completed the questionnaire appear older and more female than the respondents who did not complete the questionnaire. When appropriate statistical tests are used to compare the two groups, however, the differences are not statistically significant. Table I shows that information for the age variable and Table II for the sex variable. 
TABIE I

SIGNIFICANCE TEST FOR DIFFERENCE

IN ACE

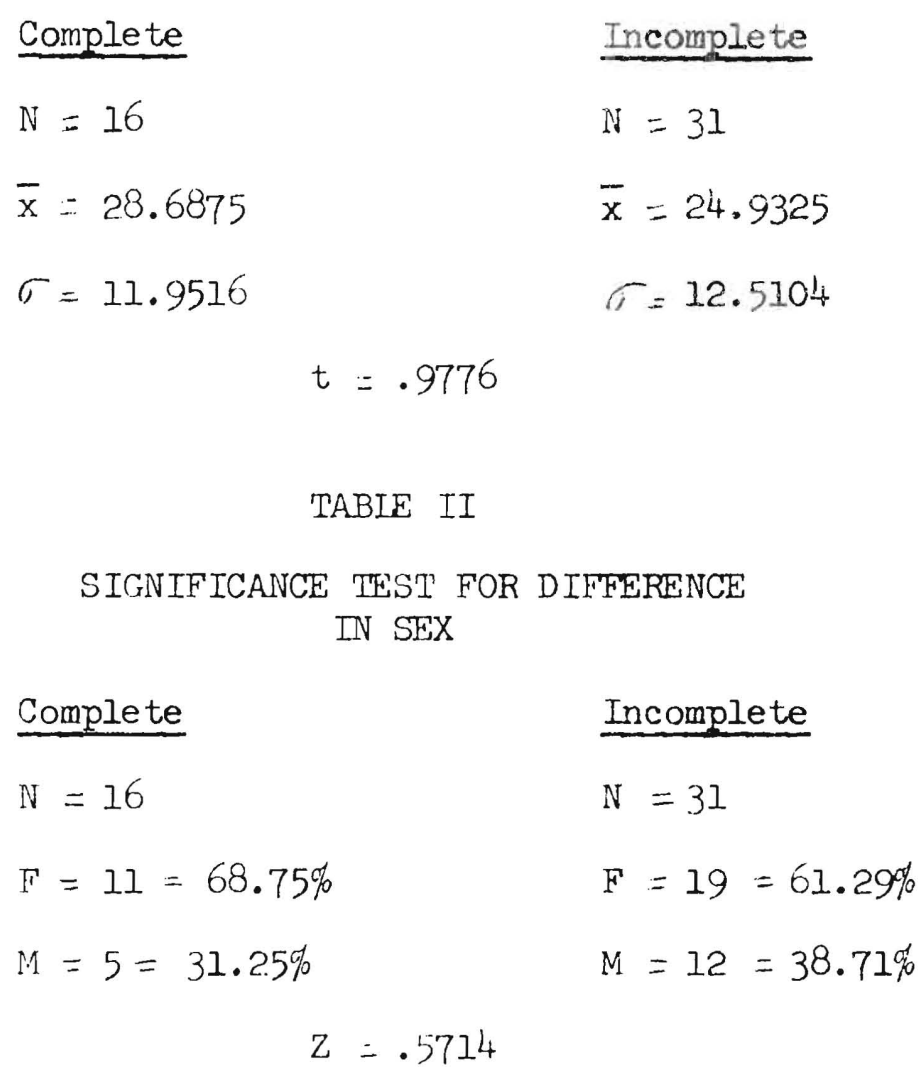

Of the 20 completed questionnaires, four are from respondents who attended two sessions or less. These will be discussed separately.

Ihere are 16 completed questionnaires from respondents who participated in from three to forty sessions. The following discussion uses information from those 16 respondents only.

First, it is helpful to look at the interviewer's comments about the respondents. Twelve respondents were found to be competent, cooperative and consistent in their answers. One respondent (1/4) was intoxicated and quite paranoid about being questioned. He completed questions $1-6$ only and refused to answer any questions after that. One adolescent ( $\left.{ }_{1 /}^{\prime l} 12\right)$ was inconsistent in her responses and answered 
with "can't remember" and "don't know" to some questions. One lady (\#/10) seemed almost too depressed to talk and was distracted by her several children at the time of the interview. One man (\#19) seemed quite slow, possibly retarded.

Responses to questions 1,2, and 3 were unanimously yes for question 1 (with the exception of \#12 who responded "don't know") and no for questions 2 and 3. Virtually all respondents were generally satisfied with the services they recelved and none had problems making appointments at convenient times or dealing with the reception desk.

Similarly, responses to questions 5 and $5 a$, whether or not the client participated in goal setting and what they thought about that practice, yielded no comparative data as the answers were the same. Respondent \#4 said he did not participate in the setting of his goal and did not like having the goal set for him. That is probably correct; he was a court referral for alcohol problems. Respondent \#12 could not remember whether or not she participated in the goal setting. The remaining 14 clients said they did participate in the setting of their therapeutic goals and responses to what they thought about that were "good" and "I liked it" (10 responses), and "that's what I came for" (4 responses).

Question 8, whether clients came on a voluntary or required basis does not ellcit the Intended response. Some respondents, known to be court referred, claimed to be voluntary. All of the clients who came to the agency presenting a marital or family problem claimed to be voluntary. In those, and other situations, voluntary may not mean that the client came of his own motivation. 
"Voluntary" means more than whether or not a court order resulted in the client comini. A court mix five a parson a cholce betwoen treatment at lilahan or jail. If the person chooses treatment, is he voluntary? In marital and family matters, the question becomes even more complicated because it is well known that couples come into treatment for many reasons, some of them having little to do with internal motivation for personal growth and change. If a husband gives an ultimatum to a wife that she must participate in therapy (either individual or marital) or he will leave her and she does partjcipate in therapy, is she voluntary?

Better information could probably be found for this question in the client's file. Also "voluntary" needs to be defined. If the idea is to make some inference about the motivation from that question, then some assessment about motivation, external and internal, should be made a) by asking the client, b) by the evaluator getting the information from the client's file, or c) from the therapist. Question 8, as it stands, is inadequate to meet any need, regardless how "voluntary" is defined.

Questions 9 and 10 were asked to ease the problems in locating respondents for the six-month follow-up and are of no present interest. That leaves questions 4,6, and 7 plus the demographic variables and the therapists' evaluations of goal achievement for analysis. Because of the small number of respondents and the nature of the data, a descriptive rather than a statistical analysis is appropriate.

Table III displays the respondent number (a sequential number used only to ease discussion of responses) in column 1, client's age, sex and number of visits to the clinic in columns 2,3 , and 4 
TABIE III

DEMOGRAPHIC INFORMATION, CLIENT RESPONSES TO SELECTED QUESTIONS, AND THERAPISTS' EVALUATIONS OF GOAL ACHIEVEMENT
(1)
(2)
(3) (4)
(5)
(6)
(7)
(8)
(9)

Respondent Number

No. of $\mathrm{Cl}$. eval.

Th. eval.

Cl. satis-

Did client

faction

learn

anything

Does cl. use what learned

$\begin{array}{rrrr}1 & 18 & M & \\ 2 & 20 & F & \\ 3 & 14 & F & 10 \\ 4 & 20 & M & \end{array}$

\section{7 yes}

no

no

\section{yes}

yes

no

no

no
yes

yes

no

no

no
yes

ith the rapy

anthing

yes

yes

yes

yes

yes

yes

yes

yes

$\begin{array}{rr}7 & 32 \\ 8 & 50 \\ 9 & 23 \\ 10 & 29\end{array}$

$\begin{array}{rr}11 & \text { yes } \\ 3 & \text { no }\end{array}$

yes
no

yes

yes

yes

yes

no

no
yes

yes

yes
yes

yes

yes

yes

$\begin{array}{rrrrr}12 & 15 & F & 5 & \text { yes } \\ 13 & 39 & M & 4 & \text { no } \\ 14 & 56 & F & 40 & \text { yes } \\ 16 & 34 & F & 20 & \text { yes } \\ & & & & \\ 17 & 25 & F & 7 & \text { no } \\ 18 & 32 & F & 15 & \text { yes } \\ 19 & 36 & M & 5 & \text { no } \\ 20 & 16 & F & 15 & \text { yes }\end{array}$

yes

yes

yes

yes

yes

yes

yes

no

yes

yes

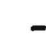

yes

yes

yes

yes

no

yes

yes

yes

yes

no

yes

yes

yes

yes

yes

yes

yes

yes

yes 
respectively, client's responses to question 4 in column 5, client's response to question 7 in column 7 , client's response to questions 6 and $6 a$ in columns 8 and 9 , and the therapists' evaluations of elient goal achievement in column 6 .

From the information in Column 5, 9 clients said they achieved therapeutic goals and 7 said they did not, or $56.25 \%$ of clients said they achieved therapeutic goals. From column 6, therapists thought $62.5 \%$ of clients achieved their goals. However, these total numbers and percentages are misleading because the 9 clients who report success and the 10 clients for whom the therapists report success are not all the same clients. It is more interesting to look at these two columns as sets of evaluations. From the data in columns 4 and 5 of Table III, Table IV enumerates those responses into sets. In each set, client response is listed first and then therapist response.

\author{
TABIE IV \\ CLIENT EVALUATION OF GOAL ACHIEVEMENT/THERAPIST \\ EVALUATION OF GOAL ACHIEVEMENT \\ 11 cases are in agreement \\ 7 cases are in agreement yes/yes \\ 4 cases are in agreement no/no \\ $\underline{5 \text { cases are in disagreement }}$ \\ 2 cases are in disagreement yes/no \\ 3 cases are in disagreement no/yes
}

The irmplications of the high level of disagreement between client and therapist evaluations of goal achievement are unknown. In this group therapists and clients disagree in nearly $1 / 3$ of the cases. 
If objectives and criteria are set as measures of goal achievement and are adequate measures, aßreement from one evaluator to another should be unanjmous.

Table $\mathrm{V}$ shows a trend that the longer the client is in therapy, the more likely he is for successful outcome recognized by himself and his therapist. There are 5 cases where clients had 1 il sessions or more, that is, at least three months of therapy usually, and all are unanimously successful on goal achievement.

\section{'LABLE V}

CLIENT EVALUATION OF' GOAL ACHIEVEMENT/THERAPIST EVALUATION OF GOAL ACHIEVEMENT LISTED BY NUMBER OF VISIIS \begin{tabular}{c} 
Number of \\
Visits \\
\hline
\end{tabular}

3
4
5
5
7

$$
10
$$$$
11
$$$$
15
$$$$
20
$$

40

$$
\begin{gathered}
\begin{array}{c}
\text { Number of } \\
\text { Cases }
\end{array} \\
\hline
\end{gathered}
$$

2

1

3

1

3

1

1

2

1

1
Client response/ the rapist response

no/no; no/no no/yes no/yes; yes/yes; no/no yes/no yes/yes; no/no; no/yes

yes/no yes/yes yes/yes; yes/yes yes/yes yes/yes

From column 7 in Table III, all clients except one who refused to answer the question, were satisfied with their therapy. It is interesting that even when goals are not achieved, clients do not fault the agency or the rapist.

Columns 8 and 9 in Table III are the responses to questions 6 and 6a respectively. Of the three clients who claim not to have learned anything, two of those also did not achieve therapeutic goals. However, 
there are 5 others who say they did not achieve therapeutic goals but did learn something. There is good consistency between whether or not anything was learned and whether or not the cllents were still using what they learned. Of the 13 who said they learned something, 12 said they still used what they learned. That question will be of even more interest as a measure of lasting value of therapy when the six-month follow-ups are done.

Of the clients who reported success on goal achievement and answered question 4d, "What did your therapist do that assisted you in reaching this goal?", 4 responses had to do with skills of the therapist and $\varepsilon$ had to do with personal qualities of the therapist. Of those who were unsuccessful, responses to $4 \mathrm{e}$, "What do you think went wrong?" were more mixed. One client was put in a group she was not ready for, one client's husband would not come in as she wanted him to for marital therapy, one client moved and one client mentioned that the therapist's skill "planted the seed" and while she did not achieve her goal during, therapy, she did achieve it subsequently. As discussed, responses to question 7, "Were you satisfied with your therapy?" were unanimously yes. Responding to question 7a, "What was effectjve about it for you?" most clients mentioned personal qualities of therapists such as "the therapist made the difference," "it was a caring relationship and I trusted his competency," "acceptance and care shown for our difficulties," "a guy you can talk to and he can tell you straight," and "the therapist was with me."

The four clients who were interviewed who dropped out after intake or intake and one session were asked questions 1, 2, 3, 7 and 8 . Responses to question 7 and their comments were of most interest. One 
client was put into a group and wanted individual therapy. Additionally, she found the therapist cold and uncaring. She said he simply walked out at the end of the session even if someone were crying, which she found very cold. She participated in only one group session. Another client's case was managed poorly from intake. The intake interview was done six weeks prior to her scheduled first appointment and then the therapist went over the intake material again which led the client to deduce that two intakes were done. In the six week interim her problems solved themselves. The other two clients in this category did not come back after intake. Both said they thought they could handle the problems themselves and one expressed difficulty in getting help for "mental" problems. 


\section{CHAPIER V}

\section{CONCLUSIONS AND RECOMMENDATIONS}

Since the completion of this pilot study, the questionnaire has been modified slightly and sent to the therapists for their comments. With the questionnaire there was also an explanation of how the data thus gathered would be shared with the therapists. Inis consists of a list of question numbers followed by four columns, the first for the responses for that therapist's clients for that month, the second for the percentage change in the therapist's total from the previous month, the third for the agency totals for that month and the fourth for the percentage change in the agency totals from the previous month. 'Ihe agency proposal. does not include sharing the results of the interviews identified by client because that would violate confidentiality.

This information is the first formal communication therapists have received regarding the follow-up study. Therapists were not asked for input nor even notified that the pilot study was being planned or implemented. This was a mistake on the part of the agency as therapists are now feeling like the process is so far along that their input is simply a formality.

Clients were not informed either of the agency's intension to do a follow-up study. Before any tclephone calls were made, clients used for follow-up should have been formally asked whether or not they would participate and asked to sign consent forms. Such forms 
are being designed now but follow-up continues on clients who have signed no such form.

Lack of respect for confidentiality of client and therapist material is the rule in this agency all in the name of administrative control. Client files are routinely reviewed by volunteers who score the therapists on proper completion of forms. And, non-therapist agency personnel use case files for various financial reasons, such as insurance billing. When interviews were being completed for this study not one respondent questioned the interviewer's access to the client's file. Clients, apparently, are not aware that they have the right to confidentiality and that therapy is traditionally a privileged relationship. Certainly, professional therapists know this. Perhaps agencies should be required to make available to every client a list of his rights and responsibilities in the therapeutic relationship. In this agency, the impetus for such action will have to come from the therapists, unless they are unfortunate enough to have a client who is aware of his rights who makes a formal complaint about their violation. The argument that therapists cannot see the follow-up data identified with names because it violates the confidentiality of the client's interview is a good argument but totally inconsistent with the remaining agency practice. So far not discussed with the therapists is the intended administrative use of the information gathered from the evaluation study. From personal conversations with the evaluator, it was learned that all the information gathered will be available to the Director and Clinical Director of the agency and that if any therapist's clients consistently fail to meet goals, the administration 
will take some form of action, possibly training in goal and objective setting and even possibly termination of the therapist in extreme cases. The administration recognizes that therapists deal with different client populations and agree that that needs to be taken into consideration when evaluating therapists but they have made no decision rules and certainly no published decision rules. They need to operationally define an "extreme case", possibly for each therapist. For an agency which insists on quantifying therapy, it seems they should follow through and quantify administrative decisions rather than ask therapists to depend on their intuitive benevolence in decision-making.

The Goal Oriented Record System used at Elahan reflects the behaviorist stance of the administration as does the evaluation instrument. Only a behaviorist would think to ask a client if he learned anything in therapy, for instance. Behaviorists see therapy as a re-learning, or a learning, experience. It can be argued, of course, that all therapists use behavioral cues to assess behavior. That is, a client is judged to be psychotic because he is behaving in a way recognized as psychotic. However, instead of a behavior, the information that goes into such a deduction includes a very complex set of behaviors as well as an assessment of thought and mood patterns. Nowhere in this record-keeping system is diagnosis or prognosis recorded because behaviorists do not recognize those terms as legitimate. One wonders, however, if it is fair to impose one theoretical framework on therapists of differing theoretical backgrounds. The most serious criticism of this study is that it fails to take into account differences, differences in theoretical philosophy 
of the therapists, and differences in client populations treated by the therapists. And, because there are no decision rules for the administrative use of the data, the unstated goals of the research should rightfully be questioned by each therapist. 
FOOTNOTES

I Weiss, "Alternative models of program evaluation," p. 676.

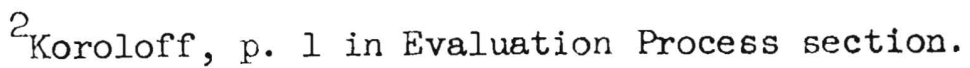

${ }^{3}$ Clarkson, p. 2-3.

${ }^{4}$ Mullen, p. 14.

5ysenck

6 Malan

$7_{\text {Malan, p. } 722 .}$

8 Malan

9 Ieary

10 Leary, p. 80.

${ }^{1} 1_{\text {Robbins }}$

$12_{\text {Kernberg }}$

13 Malan, p. 719.

14 Truax, p. 398.

15 Malan, p. 720.

16 Rubinstein

17 Strupp

18 Shlien

19 Malan, p. 726.

$2 \mathrm{O}_{\text {Weiss, }}$ "The politicization of evaluation research," p. 58.

${ }^{21}$ Attkisson, p. 751.

22 Burck, p. 3 .

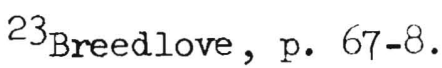


$24_{\text {Markson, p. } 727 .}$

25 Weiss, "The politicization of evaluation research," p. 61.

$26_{\text {Weiss, }}$ "The politicization of evaluation research,"p. 58.

27 Koroloff, p. 1 in Organizational Influences section,

28 Koroloff, p. 4 in Evaluative Process section.

29 Moursund, p. 14 .

30Moursund, p. 14-15.

3I Rodman, p. 125.

32 Weiss, "Alternative models of program evaluation,", p. 681.

33 Moursund, p. 9.

${ }^{34}$ Zusman, p. 353.

35 Breedlove, p. 64 .

36 Breedlove, p. 61 .

37 Breedlove, p. 56.

38 Weiss, Evaluation Research: Methods of Assessing Program Effectiveness, p. 25.

39 Moursund, p. 89.

4OMullen, p. 10.

${ }^{4} 1_{\text {Chommie, }}$. 682 .

42 Weiss, "Alternative models of program evaluation," p. 677.

43 Weiss, "Alternative models of program evaluation," p. 676.

${ }^{44}$ Moursund, p. 9.

45 Koroloff, p. 3 in Evaluative Process section.

46 Moursund, p. 9.

47 Whitehorn, p. 1 .

48 Whitehorn, p. 3 .

${ }^{49}$ Volsky, p. 175. 
50 Malan, p. 728.

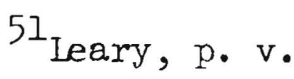

52 Leary, p. 85.

53 Milion, p. 2.

${ }^{54}$ Milion, p. 2-3.

${ }^{55}$ Milion, p. 3.

56. Millon, p. 95.

57 Millon, p. 95.

58 Millon, p. 142.

59 Millon, p. 6.

60 Breedlove, p. 68.

${ }^{6} 1_{\text {Breedlove, p. } 56 .}$

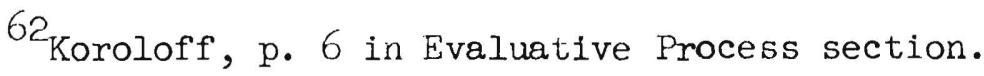

63 Moursund, p. 19.

64 Koroloff, p. 6 in Evaluative Process section.

65 Weiss, Evaluation Research: Methods of Assessing Program Effectiveness, p. 6 .

$66_{\text {Koroloff, }}$ p. 10 in Data Gathering Instruments section.

67 Koroloff, between pp 3 and 4 in Evaluative Process section.

68 Moursund, p. 10.

${ }^{69}$ Segal, p. 3.

$70_{\text {Breedlove, p. } 67 .}$

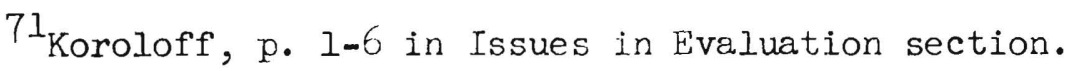

72 Weiss, "The politicization of evaluation research," p. 62.

73 Weiss, "The politicization of Evaluation research," p. 65.

74 Weiss, "The politicization of evaluation research," p. 67.

75 Weiss, "The politicization of evaluation research," p. 67. 


\section{SEIELTLD BILLIUGRAPEO}

Arnhoff, F. N., "Some factors influencing the unreliability of clinical judgements," Journal of Clinical Psychology, 10 (3), $272-5,1954$.

Attkisson, C. C., McIntyre, M. H., Hargreaves, W. A., Harris, M. R., and Ochberg, F. M., "A working model for mental health program evaluation," American Journal of Orthopsychiatry, 44(5), 741-53, 1974.

Bergin, A. E. and Jasper, L. G., "Correlates of empathy in psychotherapy: A replication," Journal of Abnormal Psychology, 74(4), $477-81,1969$.

Breedlove, J. L., "Theory development as a task for the evaluator," pp. 55-70 in Mullen, E. F. and Dumpson, J. R., (eds.), Evaluation of Social Intervention, Josey-Bass, Inc., San Francisco, 1972 .

Burck, H. D., Cottingham, H. F., and Reardon, R. C., Counseling and Accountability: Methods and Critique, Pergamon Press, Inc., New York, 1973.

Chommle, P. W. and Hudson, J., "Evaluation of outcome and process;" Social Work, 19(6), 682-87, 1974.

Clarkson, Q. D., Koroloff, N., Newberger, W., Hines, S., Goal Attalnment Scaling: A Review, Portland State University, Regional Research Institute for Human Services, Feb. 1976.

Eysenck, H. J., "The effects of Psychotherapy: An evaluation," Journal of Counseling Psychology, 16(5), 319-24, 1952.

Kernberg, O. F., et al, "Psychotherapy and psychoanalysis: Final report of the Menninger Foundation's psychotherapy research project," Bulletin of the Menninger Clinic, 36(1 \& 2), 1972.

Koroloff, N., Clarkson, Q. D., and Newberger, W. F., Program Evaluation Project, Program Evaluation Project, 1974.

Leary, 'T., Multilevel Measurement of Interpersonal Behavior, Psychological Consultation Service, Berkeley, California, 1956.

Iemkau, P. V. and Pasamanick, B., "Problems of evaluation of mental health programs," American Journal of Orthopsychiatry, 27(1), $55-8,1957$. 
Luborsky, I., "Clinicains' judgements of mental health," Archives of General Psychiatry, 7(6), 407-17, 1962.

Malan, D. H., "The outcome problem in psychotherapy research, a historical review," Archives of Ceneral Psychiatry, 29, 719-29, 1973.

Markson, E. W., et al, "Basic concepts in mental health evaluation," Hospital and Community Psychiatry, 26(11), 727-37, 1975.

Millon, T. and Diesenhaus, F., Research Methods in Psychotherapy, John Wiley and Sons, New York, 1972.

Moursund, J. P., Evaluation: An Introduction to Research Design, Brooks/Cole, Monterey, California, 1973.

Mullen, E. F. and Dumpson, J. R., "Is social work on the wrong track?" pp. I-14 in Mullen, E. F. and Dumpson, J. R., (eds.), Evaluation of Social Intervention, Josey-Bass, Inc., San Francisco, 1972.

Robbins, L. I., et al, "The psychotherapy research project of the Menninger Foundation," Bulletin of the Menninger Clinic, $20(5), 221-78,1956$.

Rodman, H. and Kolodny, R., "Organizational strains in the researcherpractioner relationship," pp. 117-36 in Caro, F. G. (ed.) Readings in Evaluation Research, Russell Sage Foundation, New York, 1971.

Rubinstein, E. A. and Parloff, M. B., (eds.) Research in Psychotherapy, Volume I, (Proceedings of a conference of the American Psychological Association, 1958), American Psychological Association, Washington, D.C., 1959.

Segal, S. P., "Research on the outcome of social work therapeutic interventons: A review of the literature," Journal of Health and Social Behavior, 13(1), 3-17, 1972.

Shlien, J. (ed.), Research in Psychotherapy, Volume III, (Proceedings of a conference of the American Psychological Association, 1966), American Psychological Association, Washington, D.C., 1968.

Strupp, H. H., and Luborsky, L. (eds.), Research in Psychotherapy, Volume II, (Proceedings of a conference of the American Psychological Association, 1961), American Psychological Association, Washington, D. C., 1962.

Susser, M., Community Psychiatry: Epidemiological and Social Themes, Random House, New York, 1968. 
Truax, C. A., "Therapist empathy, genuineness and patient the rapeutic outcome," Journal of Consulting Psychology, 30, 395-401, 1966.

Volsky, T., Magoon, T. M., Norman, W. T. and Hoyt, D. P., The Outcomes of Counseling and Psychotherapy: Theory and Research. University of Minnesota Press, Minneapolis, 1965.

Weiss, C. H., "Alternative models of program evaluation," Social Work $19(6), 675-81,1974$.

Weiss, C. H., "Evaluating educational and social action programs: A treeful of owls," pp. 3-27 in Weiss, C. H., Evaluating Action Programs: Readings in Social Action and Education, Allyn and Bacon, Inc., Boston, 1972.

Weiss, C. H., Evaluation Research: Methods of Assessing Program Effectiveness, Prentice-Hall, Inc., Englewood Cliffs, 1972.

Weiss, C. H., "The politiclzation of evaluation research," Journal of Social Issues, 26(4), 57-68, 1970.

Weiss, C. H., "Utilization of evaluation: toward comparative study," pp. 136-5I in Caro, F. G. (ed.), Readings in Evaluation Research, Russell Sage Foundation, New York, 1971.

Whitehorn, J. C., "Goals of Psychotherapy" pp. 1-9, in Rubinstein, E. A. and Parloff, M. B., (eds.), Research in Psychotherapy, Volume I, American Psychological Association, Washington, D. C., 1959.

Zusman, J. and Ross, E. R. R., "Evaluation of the quality of mental health services," Archives of General Psychiatry, 20(3), 352-7, 1969. 
XI CNGAd $\forall$ 
INFORMATION FROM CLIENT FIIE

Client's Name

- Age

- Sex

Marital Status

- Intake Date

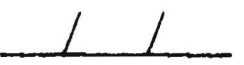

Date of Iast Session

11

Client's Therapist(s)

Number of Visits

- Severity Scores from Intake Summary

$\begin{array}{ll}\text { Work } & \text { Child } \\ \text { Domestic } & \text { Spouse } \\ \text { Student } & \text { Parental } \\ \text { Legal } & \text { Other }\end{array}$

Objective for First Priority Goal* and its Criterion should be Written into Question 4 of the Questionnaire. * (if more than one first priority goal, choose the earliest one recorded).

-Client's Telephone at home at work

Collateral telephone, if any

- First 'Telephone Try:

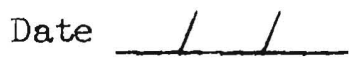

Second Telephone Try: Date 11

Third Telephone Try: Date 11 
FOLLOW-UP SURVEY QUESTIONNA IRE

for the

Evaluation Department

Elahan Center for Mental Health and Family Living

I'd like to speak to - Hello, my name is I work in the Evaluation Department at Elahan mental health in Vancouver. We are conducting a survey of people who have used our services. I would like your help in answering some questions about your experience with the center. Your answers will be used to make improvements in our services, so we need to know what you really think.

1. Were you satisfied with the services you received at the mental health center?

\section{YES}

INO - I'll ask you more about that as we continue with the interview.

YES $2 a$. What days and times would have been better?

2. Was there any inconvenience with your appointment times?

ivo

YES $3 e$ What was the problem?

3. Did you have any problems

with our telephone service or the reception desk? 
YES $4 a$ Is this change stil in effect today? YES NO

4b Have you done even better than this goal? YES NO

4. While you were at the center, a treatment goal was set for you which read

4c What did your therapist do that assisted you in reaching (or exceeding) this goal?

By the end of therapy did you reach this goal?

iNO id Have you reached the goal since the end of the rapy? YES NO 4e What do you think went wrong?

YES 5 a what do you think about this?

5. Did you participate in setting the goals for your therapy?

NO 5 a what do you think about this?

6. Did you learn anything while you were in

YES 6 a Do you still use what you learned? YES NO the rapy? 
YES $7 a$ What was effective about the therapy for you?

7. Were you satisfied with your therapy?

NO $7 \mathrm{~b}$ Why not?

8. Did you come to the center WANTED TO because you wanted to, or were you required to for any reason?

REQUIRED

9. May we check with you in YES six months to see how you're doing?

NO

YES

10. Will you still be at the same 'phone number in six months?

NO 10a Is there another 'phone number where I could find out your new one after you move?

11. That's a.ll the questions YES

I have. Is there anything else you'd like to say?

NO

Interviewer's Name Date of Interview

Interviewer's Comments 